\title{
Caracterização da inviabilidade evolutiva de embriōes visando doações para pesquisas de células-tronco
}

\author{
Characterization of unviable embryos suitable for donation to stem-cell research
}

Nilka Fernandes Donadio ${ }^{1}$, Nilson Donadio ${ }^{2}$, Carlos Oliveira Celestino ${ }^{3}$, Tsutomu Aoki ${ }^{4}$

\section{RESUMO}

Objetivo: estabelecer quais as características que definem um embrião como inviável, tornando-o passível de doação para pesquisa com células-tronco. Métodos: avaliação retrospectiva de ciclos de fertilização in vitro realizados entre janeiro de 1995 a 2005. Foram selecionados ciclos nos quais se transferiram para a cavidade uterina embriões com classificações morfológicas iguais entre si. Desta forma, avaliaram-se as taxas de gravidez, implantação e involução de sacos gestacionais dos embriões frescos e criopreservados, distribuídos em grupos, de acordo com sua morfologia. Foram considerados embriões tipo A aqueles simétricos e sem fragmentação; tipo B, assimétricos ou com até $25 \%$ de fragmentação; tipo C, com 25 a $50 \%$ do seu volume ocupado por fragmentos, e tipo D, aqueles com $50 \%$ ou mais de fragmentação. Para as análises estatísticas utilizaram-se os testes de Kruskal-Wallis e Mann-Whitney. Resultados: em 87 ciclos foram transferidos 172 embriões tipo D, obtendo-se 11\% de gravidez, embora somente metade dos embriões inicialmente implantados manteve sua evolução. Já embriões de mesma morfologia quando criopreservados, após descongelamento, não mostraram capacidade evolutiva, apresentando, a partir da transferência de 113 embriões em 36 ciclos, somente uma implantação, perfazendo uma diminuta taxa de 3\% de gravidez. Aúnica gestação obtida involuiu antes da $12^{\mathrm{a}}$ semana de gestação. Conclusão: embriões de baixos escores morfológicos não podem ser considerados inviáveis por serem capazes, embora com uma freqüência muito baixa, de promoverem gestação. Mas estes mesmos embriões, quando criopreservados e posteriormente transferidos após descongelamento, mostraram taxa de gravidez irrisória, além de não resultarem em gravidez viável. Logo, quando extranumerários, os embriões tipo D não deveriam ser criopreservados, podendo então, ao invés de serem descartados, ser doados para pesquisa de células-tronco embrionárias.

PALAVRAS-CHAVE: Células-tronco; Embrião; Fertilização in vitro; Morfologia; Criopreservação

\section{ABSTRACT}

Purpose: to define the characteristics of unviable embryos that may be donated for stem-cell research. Methods: a retrospective evaluation of in vitro fertilzation cycles between January 1995 and January 2005 was structured. Cycles were chosen in which the embryos transferred to the uterine cavity had the same morphological characteristics. Subsequently, the rates of pregnancy, implantation, and involution of the gestational sacs of the fresh embryos as well as of those cryopreserved were analyzed and distributed into groups according to their morphology. Embryos that were symmetric and with $0 \%$ of fragmentation were designated type $\mathrm{A}$; asymmetric with up to $25 \%$ of fragmentation were designated type $\mathrm{B}$; between 25 and $50 \%$ of volume occupied were designated type $\mathrm{C}$, and those with $50 \%$ or more of fragmentation were designated type $\mathrm{D}$. Results: one hundred and seventy-two type D embryos transferred in 87 cycles presented low rates of implantation (11\%) with 50\% of those implanted persisting in development. Embryos with the same morphology, after cryopreservation and thawing, did not show the capacity to evolve. In 36 cycles, 113 thawed type D embryos were transferred, resulting in only one implantation, presenting a minute 3\% pregnancy rate. The implanted gestational sac did not evolve, showing a 100\% rate of involution. Conclusion: embryos with low morphological scores cannot be considered unviable because they are capable, even though with a very low frequency, of supporting gestation. However, these same embryos, after cryopreservation, thawing and transfer showed an

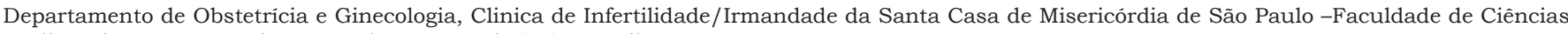
Médicas da Santa Casa de São Paulo - São Paulo (SP) - Brasil.

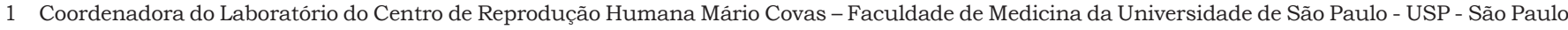
(SP) - Brasil. Diretora do Pro-Embryo - Centro Avançados de Técnicas em Reprodução Assistida.

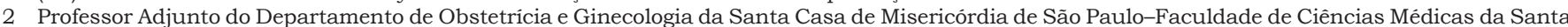
Casa de São Paulo; Diretor Geral do Pro-Embryo Centro Avançado de Técnicas em Reprodução Assistida

3 Biólogo do Pro-embryo Centro Avançado de Técnicas em Reprodução Assistida - São Paulo (SP) - Brasil.

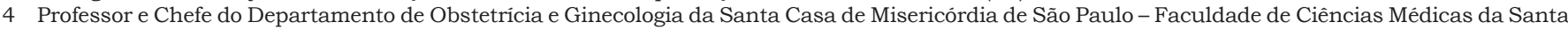
Casa de São Paulo - São Paulo (SP) Brasil.

Correspondência: Nilka Donadio, MD

Rua Bartira, 857 - Perdizes - 05009-000 - São Paulo - SP - Fone: (11) 38622705 - Fax: (11) 38729817 - e-mail: emit@ig.com.br 
insignificant rate of pregnancy, that did not result in viable pregnancy. Therefore, when in excess to requirements, type D embryos should not be cryopreserved; instead, rather than discarded, they should be donated for embryo stem-cell research.

KEYWORDS: Stem cells; Embryo; Fertilization in vitro; Morphology; Cryopreservation

\section{Introdução}

Assunto polêmico e promissor, o desenvolvimento de células-tronco embrionárias humanas, que teve início com as pesquisas de Thomson et al. ${ }^{1}$, em 1998, vem sendo palco de infindáveis discussões religiosas, éticas e legais ${ }^{2-4}$. A destruição de blastocistos, com utilização da sua massa celular interna ${ }^{5}$, para obtenção de células totipotentes capazes de se desenvolver em qualquer tecido dos três folhetos germinativos, além dos tecidos extra-embrionários ${ }^{6}$, visando terapia celular se$\mathrm{ria}^{7}$, eventualmente, justificável. "Um embrião, potencial de vida, em troca do tratamento de inúmeras outras vidas já existentes" ${ }^{\text {. Lembrando-se }}$ sempre que tudo ainda é experimental.

A utilização de células-tronco adultas talvez promova os mesmos resultados, embora a maioria dos trabalhos da literatura discorde, por estas últimas aparentemente possuírem menor potencial de diferenciação ${ }^{9-11}$. Além disso, a resposta quanto à igualdade ou não entre os resultados só será possível se trabalharmos com ambas as linhagens tronco, adultas e embrionárias ${ }^{12}$. As posições quanto à origem dos embriões utilizados para obtenção das células-tronco são irreconciliáveis mas é quase unânime a posição de que não se deve criar embriões especificamente para esta finalidade e sim utilizar aqueles extranumerários existentes nas clínicas de reprodução assistida ${ }^{12}$.

Por fim, em 24 de março deste ano de 2005 foi aprovada no Congresso Nacional a Lei 11.105/ 05 de biossegurança, que em seu artigo $5^{\circ}$ permite, para fins de pesquisa e terapia, a utilização de células-tronco embrionárias obtidas de embriões humanos produzidos por fertilização in vitro e não utilizados no respectivo procedimento. Para isto devem ser atendidas as seguintes condições: sejam embriões inviáveis; ou sejam embriões congelados há três anos ou mais, na data da publicação da Lei, ou se já congelados na data da publicação da Lei, depois de completarem três anos, contados a partir da data de congelamento.

Cabe ainda definir o que significa exatamente embrião inviável. A inviabilidade poderia ser interpretada como parada completa de desenvolvimento $^{13,14}$ : morte embrionária. Neste caso nada mais resta que o descarte do embrião, pois nem mesmo para doação de célula-tronco ele se prestaria. Então o conceito de inviabilidade não seria diretamente do embrião, mais sim, da inviabili- dade da obtenção de gestação viável a partir deste embrião. Surgem, assim, dois raciocínios: a inviabilidade genética, caracterizada por alterações do embrião comprovadas pelo diagnóstico préimplantacional, incompativeis com a vida, ou que não foram comprovadas por falhas da técnica, mas com elevado risco ${ }^{12}$; e a inviabilidade evolutiva, ou seja, quando a transferência uterina do embrião não resultaria em gravidez.

Habitualmente a seleção de embriões é realizada a partir de critérios morfológicos bem estabelecidos, como tempo de clivagem, fragmentação, simetria, multinucleação e aspectos citoplasmáticos dos blastômeros, além da avaliação precoce dos pró-núcleos ${ }^{15-18}$.

Quanto à clivagem, embriões com 48 horas de evolução devem apresentar quatro ou mais blastômeros, e com 72 horas, seis ou mais blastôme$\operatorname{ros}^{19-22}$. A ausência de nova clivagem por um período superior a 24 horas caracteriza a parada evolutiva do embrião ${ }^{14,22,23}$.

A fragmentação é considerada um dos critérios morfológicos mais importantes da avaliação embrionária. Em uma das classificações de embriões mais utilizadas, desenvolvida por Veeck ${ }^{24}$, em 1986, embriões sem fragmentação e simétricos são denominados tipo $\mathrm{A}$, aqueles assimétricos com até $25 \%$ de fragmentação tipo B, o tipo C apresenta entre 25 a $50 \%$ de fragmentação e tipo D $50 \%$ ou mais. Outras classificações incluem diferentes parâmetros, como distribuição dos fragmentos ${ }^{25}$, multinucleação $^{26,27}$ e característica do citoplasma ${ }^{22}$, mas mantêm o volume ocupado por fragmentos como principal critério. Sabidamente, quanto pior a morfologia, menores as chances de implantação e gravide $z^{20,22,25}$.

Baseando-se nestes critérios morfológicos, este trabalho tem como objetivo discutir e buscar a caracterização dos embriões evolutivamente inviáveis passíveis de doação para pesquisa com células-tronco embrionárias.

\section{Métodos}

Coletaram-se os dados do Centro Biológico de Reprodução Humana da Santa Casa de Misericórdia de São Paulo e do Pró-embryo, Centro de técnicas avançadas em Reprodução Assistida, referentes a todos os procedimentos de fertilização in vitro realizados entre janeiro de 1995 e janeiro de 2005 . $\mathrm{O}$ estudo foi dividido em duas etapas. Na pri- 
meira etapa comparamos as taxas de gravidez e de implantação entre os embriões normalmente clivados tipo A, B, C e D, avaliando-se assim a capacidade destes em proporcionar gestações viáveis de acordo com sua morfologia. Para isso foram incluídos os casos nos quais o pool de 1 a 4 embriões utilizados para a transferência uterina foi homogêneo, ou seja, quando todos os embriões eram morfologicamente iguais entre si, sendo excluídos os casos de transferências mistas, ou melhor, nos quais no grupo de embriões transferidos havia embriões de diferentes classes morfológicas. A necessidade de exclusão ocorre pela impossibilidade de reconhecermos nos casos de transferências de embriões qualitativamente diferentes, qual dentre eles teve êxito na implantação.

Distribuímos os casos em quatro grupos: Grupo A - casos em que foram transferidos de 1 a 4 embriões, todos com morfologia tipo A (simétricos com 0\% de fragmentação); Grupo B - em que foram transferidos de 1 a 4 embriões com morfologia tipo B (assimétricos até $25 \%$ de fragmentação); Grupo C - transferências de embriões, todos com morfologia tipo C (25 a 50\% do seu volume ocupado por fragmentos); Grupo D - somente embriões com morfologia tipo D (acima de 50\% de fragmentação). Calcularam-se as taxas de gravidez de cada grupo, dividindo-se o total de casos com ultrasonografia mostrando presença de saco gestacional, realizada na $6^{\mathrm{a}}$ semana de gestação, pelo total de integrantes do respectivo grupo. Calcularamse também as taxas de implantação, dividindo-se o total de sacos gestacionais verificados à ultrasonografia, pelo total de embriões transferidos. Avaliando-se os exames ultra-sonográficos realizados com 12 semanas de gestação, a partir das involuções de alguns sacos gestacionais, obtiveram-se as taxas de perdas gestacionais iniciais.

As diferenças estatísticas entre os grupos foram avaliadas utilizando-se os testes de KruskalWallis e Mann-Whitney, sendo considerados significativos valores de $\mathrm{p}$ inferiores a 0,05.

$\mathrm{Na}$ segunda etapa do estudo, objetivou-se comparar a sobrevida e a viabilidade de embriões tipo A, B, C e D pós-criopreservação. Embora muitos centros só criopreservem embriões multicelulares de boa qualidade, nossa conduta sempre foi o congelamento de todos os extranumerários, a não ser quando comprovada a parada evolutiva (ausência de clivagem por período superior a 24 horas) ou não integridade da zona pelúcida, como descrito por Lightman et al. ${ }^{28}$, em 1997. Todas as criopreservações foram realizadas conforme técnica previamente descrita ${ }^{29}$, com transferência 2 a 4 horas pós-descongelamento daqueles embriões com integridade de pelo menos $50 \%$ de seus blastômeros. Considerou-se a taxa de perda embrionária (embriões com mais do que 50\% de blastômeros inviáveis) pós-descongelamento para cada grupo morfológico. De modo semelhante foram incluídos, para obtenção das taxas de gravidez e implantação, casos em que todos os embriões utilizados nas transferências eram de igual morfologia prévia ao congelamento. A distribuição se deu em quatro grupos, sendo no Grupo A_crio incluídos os casos em que foram transferidos de um a quatro embriões descongelados, sendo que todos apresentavam morfologia tipo A na data da criopreservação; Grupo B_crio - transferência de embriões descongelados, sendo que todos apresentavam morfologia tipo B na data da criopreservação; Grupo C_crio - casos de transferências de embriões descongelados, sendo que todos apresentavam morfologia tipo $\mathrm{C}$ na data da criopreservação; e por fim Grupo D_crio - em que se transferiu embriões descongelados, todos com morfologia tipo D na data da criopreservação. Calcularam-se de forma semelhante as taxas de gravidez, implantação e perda gestacional inicial de cada grupo.

\section{Resultados}

De um total de 9.327 ciclos realizados entre janeiro de 1995 e Janeiro de 2005, foram incluídos na primeira etapa do respectivo estudo 533 casos, sendo estes distribuídos conforme a Tabela $1 . \mathrm{Na}$ mesma tabela se mostra o número total de embriões por grupo distribuídos conforme a transferência de um, dois, três e quatro embriões. Resumidamente, foram avaliadas as evoluções de 337 embriões tipo A, 436 tipo B, 223 tipo C e 172 tipo D.

Tabela 1 - Total de casos e embriões incluídos nos grupos A, B, C e D.

\begin{tabular}{lcccccc}
\hline Grupo & $\begin{array}{c}\text { Número de } \\
\text { casos/grupo }\end{array}$ & $\begin{array}{c}\text { Transferência } \\
\text { de embrião único }\end{array}$ & $\begin{array}{c}\text { Transferência } \\
\text { de dois embriões }\end{array}$ & $\begin{array}{c}\text { Transferência } \\
\text { de três embriões }\end{array}$ & $\begin{array}{c}\text { Transferência } \\
\text { de quatro embriões }\end{array}$ & $\begin{array}{c}\text { Total de embriões } \\
\text { por grupo }\end{array}$ \\
\hline A & 146 & 28 & 59 & 45 & 14 & 337 \\
B & 198 & 43 & 95 & 37 & 23 & 436 \\
C & 102 & 33 & 27 & 32 & 10 & 223 \\
D & 87 & 51 & 9 & 5 & 22 & 172 \\
Total & 533 & 155 & 190 & 119 & 69 & 1168 \\
\hline
\end{tabular}

Grupo A - casos em que foram transferidos de 1 a 4 embriões, todos com morfologia tipo A (simétricos com $0 \%$ de fragmentação); Grupo B - transferidos de 1 a 4 embriões com morfologia tipo B (assimétricos até $25 \%$ de fragmentação); Grupo C - todos os embriões, com morfologia tipo C ( 25 a $50 \%$ do seu volume ocupado por fragmentos); Grupo D - somente embriōes com morfologia tipo $D$ (mais que $50 \%$ de fragmentação). 
Na segunda etapa do estudo foram incluídos 215 casos, sendo avaliados um total de 795 embriões criopreservados, distribuídos nos grupos conforme a Tabela 2. Excluíram-se aqueles embriões que após o descongelamento não apresentaram sobrevida de nenhum de seus blastômeros, restando então para as transferências, 133 embriões no grupo A_crio, 115 no B_crio, 164 no C_crio e por fim, 113 no Grupo D_crio, perfazendo um total de 525 embriões. A taxa de sobrevida pós-descongelamento de cada tipo morfológico embrionário está representada na mesma tabela.

Tabela 2 - Número de casos e embriões transferidos incluídos nos Grupos A_crio, B_crio, C_crio e D_crio.

\begin{tabular}{lcccccccc}
\hline Grupo & Casos & $\begin{array}{c}\text { Número inicial } \\
\text { de embriões }\end{array}$ & $\begin{array}{c}\text { Percentual de } \\
\text { perdas pós- } \\
\text { descongela } \\
\text { mento }\end{array}$ & $\begin{array}{c}\text { Transferência de } \\
\text { embrião único }\end{array}$ & $\begin{array}{c}\text { Transferência } \\
\text { de } 2 \text { embriões }\end{array}$ & $\begin{array}{c}\text { Transferência } \\
\text { de } 3 \text { embriões }\end{array}$ & $\begin{array}{c}\text { Transferência } \\
\text { de } 4 \text { embriões }\end{array}$ & $\begin{array}{c}\text { Total de } \\
\text { embriões } \\
\text { transferidos } \\
\text { por grupo }\end{array}$ \\
\hline A_crio & 66 & 157 & $15,3 \%$ & 21 & 25 & 18 & 2 & 133 \\
B_crio & 49 & 161 & $28,6 \%$ & 11 & 16 & 16 & 6 & 115 \\
C_crio & 64 & 261 & $37,1 \%$ & 19 & 14 & 7 & 24 & 164 \\
D_crio & 36 & 216 & $47,7 \%$ & 3 & 6 & 10 & 17 & 113 \\
TOTAL & 215 & 795 & $34 \%$ & 54 & 61 & 51 & 49 & 525
\end{tabular}

Grupo A_crio - casos em que foram transferidos de 1 a 4 embriões descongelados, todos com morfologia tipo A (simétricos com 0\% de fragmentação) na ocasião da criopreservação; Grupo B_crio - transferidos de 1 a 4 embriões descongelados com morfologia tipo B (assimétricos até $25 \%$ de fragmentação) na data da criopreservação; Grupo C_crio - todos os embriões descongelados, com morfologia tipo C ( 25 a $50 \%$ do seu volume ocupado por fragmentos) na data da criopreservação; Grupo D_crio - somente embriốes descongelados com morfologia tipo D (mais que $50 \%$ de fragmentação) na data da criopreservação.

A Tabela 3 resume as taxas de gravidez, imconcomitantemente nos oito grupos do estudo. plantação e involução obtidas pós-transferência

Tabela 3 - Taxas de gravidez, implantação e perdas gestacionais em cada grupo.

\begin{tabular}{|c|c|c|c|c|c|}
\hline Grupo & $\mathrm{n}$ & Taxa de gravidez & $\begin{array}{c}\text { Número de embriões } \\
\text { transferidos }\end{array}$ & Taxa de implantação & Taxa de perda \\
\hline$A$ & 146 & $42 \%$ & 337 & $28 \%$ & $13 \%$ \\
\hline B & 198 & $38 \%$ & 436 & $25 \%$ & $7 \%$ \\
\hline C & 102 & $24 \%$ & 223 & $12 \%$ & $33 \%$ \\
\hline$D$ & 87 & $11 \%$ & 172 & $6 \%$ & $50 \%$ \\
\hline A_crio & 66 & $23 \%$ & 133 & $13 \%$ & $13 \%$ \\
\hline C_crio & 64 & $5 \%$ & 164 & $2 \%$ & $67 \%$ \\
\hline D_crio & 36 & $3 \%$ & 113 & $0,8 \%$ & $100 \%$ \\
\hline Total & 748 & $26 \%$ & 1693 & $16 \%$ & $17 \%$ \\
\hline
\end{tabular}

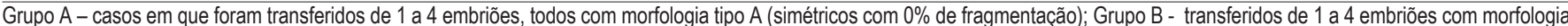

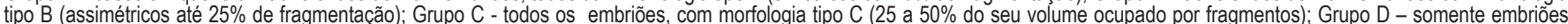

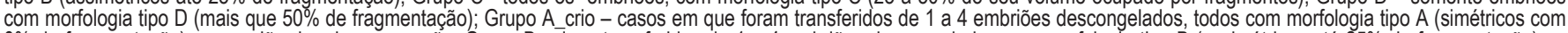

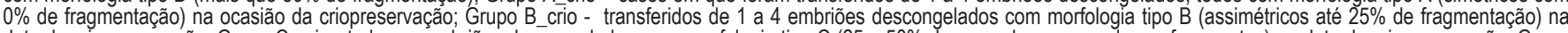

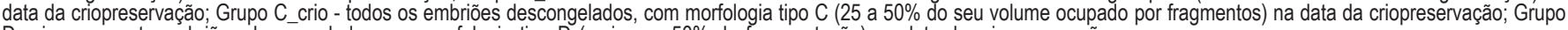
D crio - somente embriões descongelados com morfologia tipo D (mais que $50 \%$ de fragmentação) na data da criopreservação.

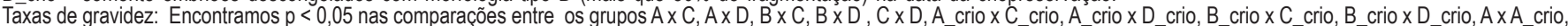
B x B_crio, C x C_crio e D x D_crio

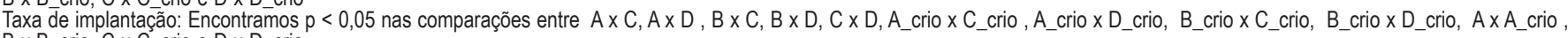
B x B_crio, C x C_crio e D x D_crio

Taxa de perda inicial: Encontramos $p<0,05$ nas comparações entre $A \times C, A \times D, B \times C, B \times D, A$ crio x C_crio, e A_crio x D_crio

Quanto às taxas de gravidez, não foram encontradas diferenças estatísticas quando comparados os grupos A $(42 \%)$ e $\mathrm{B}(38 \%)(\mathrm{p}=0,391)$, A_crio $(23 \%)$ e B_crio $(16 \%)(\mathrm{p}=0,398)$ e entre o grupo C_crio $(5 \%)$ e D_crio $(3 \%)(\mathrm{p}=0,642)$. Todas as outras correlações entre os grupos mostraram diferenças estatisticamente significantes.

As taxas de implantação encontradas nos grupos A, B, C e D foram de 28, 25, 12 e 6\%, respectivamente. Entre aqueles criopreservados obtivemos $13 \%$ no grupo A_crio, $10 \%$ no B_crio, $2 \%$ no C_crio e $0,8 \%$ no D_crio. Correlacionando as taxas de implantação, não houve diferença estatística entre os grupos A e B, A_crio e B_crio, e entre C_crio e D_crio.
Os embriões de pior morfologia apresentaram elevadas taxas de involução das gestações inicialmente implantadas, sendo 33\% no grupo C, 50\% no grupo D e chegando a 67 e 100\% nos grupos C_crio e D_crio. As diferenças entre as perdas gestacionais iniciais foram significativas entre os grupo A e C, A e D, B e C, B e D, A_crio e C_crio e A_crio e D_crio.

\section{Discussão}

Inúmeros estudos da literatura mostram a correlação direta da qualidade embrionária com 
as taxas de gravide $z^{20,22,23,25}$. Independente da forma ou escore utilizado na avaliação, quanto pior a morfologia, ou seja, quanto maior a fragmentação e assimetria, menores as chances de implantação. Como exemplo, Ziebe et al. ${ }^{30}$, em 1997, mostraram taxas de implantação de $28 \%$ com embriões tipo A e somente $5 \%$ com embriões D.

Poucos são os trabalhos que relatam a obtenção efetiva de gestação com embriões altamente fragmentados ${ }^{31}$. Trabalho de Ziebe et al. ${ }^{30}$, anteriormente comentado, mostrou $15 \%$ de gestação contra $43 \%$ obtida na transferência de embriões qualitativamente superiores. Giorgetti et al. ${ }^{20}$, em 1995, avaliando 957 transferências de um único embrião, mostraram taxa de gravidez ainda menor, de 4,5\% quando transferido embrião tipo D. Staessen et al. ${ }^{17}$ obtiveram uma única gestação a partir de 68 transferências de embriões com alto índice de fragmentação; já em outra publicação, Shulman et al. ${ }^{32}$ não obtiveram, nem ao menos uma gestação.

Apesar de embriões tipo D serem capazes de iniciar uma gravidez, segundo alguns autores as chance de nascimento são muito baixas ${ }^{30}$, por exemplo Giorgetti et al. ${ }^{20}$ obtiveram somente 3,8\% de nascidos.

Thomas Ebner et al. ${ }^{31}$ alertam quanto às taxas de malformação fetal com embriões C e D serem respectivamente de 13,3 e $36,4 \%$, fato possivelmente explicável pelo maior índice de apoptose, desordem cromossômica $^{32}$ e perda de proteínas reguladoras ${ }^{33}$. Alguns trabalhos contra-indicam a transferência de embriões muito fragmentados, só o fazendo após assinatura de consentimento informado pelo casal ${ }^{31}$.

São freqüentes as discussões sobre a eventual superioridade da taxa de abortamento entre embriões morfologicamente mais comprometidos. Devido ao diminuto número de casos em que somente estes embriões são transferidos, não se podem obter conclusões definitivas ${ }^{17,20,31}$.

Em nosso estudo encontramos $11 \%$ de gestação com $6 \%$ de implantação no grupo $\mathrm{D}$ e respectivamente 24 e $12 \%$ no grupo C, não havendo diferenças estatísticas entre os dois grupos, mas quando comparadas às taxas de 42 e $28 \%$ do grupo A e 38 e $25 \%$ do grupo B, respectivamente, as diferenças foram estatisticamente comprovadas. São taxas semelhantes às encontradas na literatura, que vêm a comprovar a pequena, mas não ausente capacidade evolutiva destes embriões, mesmo apresentando graves alterações morfológicas. Além destes números, verificamos maior índice de involuções de sacos gestacionais originários de embriões $\mathrm{C}$ e $\mathrm{D}$, sendo o resultado também estatisticamente significante.

Por estes dados não podemos considerar embriões tipo C e D como absolutamente inviáveis, uma vez que, mesmo suas taxas de implantação sendo baixas, ainda assim podem levar a gestação com nascimento, embora com maiores chances de perdas gestacionais.

Quanto à segunda etapa de nosso estudo, na qual estudamos a diferença de viabilidade dos embriões descongelados, relacionando a sua qualidade morfológica prévia à criopreservação, a literatura destaca que existe relação direta entre a morfologia embrionária e o prognóstico posterior ao descongelamento $^{27,34}$. O congelamento promove redução nas taxas de implantação quando comparadas aos embriões frescos de mesma qualidade, devido às freqüentes perdas de blastômeros no processamento ${ }^{35}$. Não objetivamos neste estudo avaliar a modificação da classe morfológica pós-criopreservação dos embriões, não sendo estes dados considerados.

Segundo nosso trabalho notamos que a taxa de sobrevida embrionária é significativamente inferior nos grupos C_crio e D_crio, dado que corresponde aos achados da literatura, que concluem ser muitas vezes inviável o congelamento de embriões fragmentados e assimétricos. No grupo C_crio obtivemos $5 \%$ de gravidez com $2 \%$ de implantação. Mesmo as taxas sendo consideradas muito baixas, e associadas a uma incidência de $67 \%$ de involução gestacional, obtiveram-se gestações viáveis a partir deste grupo. Dentre os embriões tipo D na data do congelamento, além do maior índice de perdas, obtivemos somente 3\% de gravidez, com a irrisória taxa de $0,8 \%$ de implantação, e com $100 \%$ de involução destas. Não houve nenhuma gestação viável evolutiva. Estes dados que mostram a inviabilidade pós-descongelamento de embriões do tipo D. Críticas poderiam ser feitas quanto ao pequeno numero de gestações avaliadas para a conclusão quanto à inviabilidade. Vale lembrar que um total de 113 embriões foram inicialmente transferidos, número considerado significativo, e mesmo assim obtivemos só uma gestação, a qual não evoluiu; logo, a conclusão é válida.

Grande parte dos serviços não criopreserva embriões de má qualidade, descartando-os ou doando-os diretamente para pesquisa quando legalmente aprovado, justamente pelos resultados desanimadores ${ }^{23}$. Alguns serviços orientam aos casais só criopreservarem embriões supranumerários se em número superior a quatro, com quatro células ao redor de 48 horas ou sete ou mais células com 72 horas, e se estes apresentarem no máximo $10 \%$ de fragmentação ${ }^{3}$.

Podemos então concluir que embriões tipo $\mathrm{D}$ frescos são viáveis, mas congelados passam a ser inviáveis. Logo, qual a conduta diante de embriões extranumerários, além de 4 permitidos para a transferência uterina, tipo $D$, uma vez que congelá-los acaba por inviabilizá-los?

Trabalhos mostram que até mesmo para pesquisa, embriões de pobre morfologia pós-crio- 
preservação não seriam aproveitáveis, pois estes dificilmente atingem estádio de blastocisto, impossibilitando a obtenção da massa celular interna para obtenção de células totipotentes. Em contrapartida, recente estudo utilizando $130 \mathrm{em}$ briões de baixos escores morfológicos, com 72 horas de evolução, que seriam descartados pela baixa probabilidade de implantação e gestação, obteve $14,62 \%$ de blastocistos que resultaram em duas linhagens de células-tronco. Dentre estes 130 embriões, aqueles com pior grau de fragmentação realmente não evoluíram ${ }^{23}$.

Outro fato importante a ser considerado diz respeito ao potencial de obtenção de células-tronco a partir de embriões congelados há 3 anos ou mais $^{36}$. Hoffman et al. ${ }^{37}$, em trabalho publicado em 2003, levantaram, junto a todos os centros de reprodução assistida, que existem aproximadamente 400.000 embriões congelados nos EUA, e que destes somente $2,8 \%$ são viáveis para doação, perfazendo um total de 11.000, pois os embriões restantes se encontram armazenados visando o tratamento de infertilidade dos casais. Os 11.000 embriões doados para pesquisa têm qualidade questionável, pois os melhores embriões são transferidos a fresco, sendo congelados os de pior morfologia, além de o tempo de congelamento e as técnicas utilizadas serem variadas entre os serviços. Por estes aspectos, o trabalho calcula perda embrionária ao redor de $35 \%$, restando hipoteticamente, dos 11.000 iniciais, somente 7.334. Destes, somente $25 \%$ chegariam a blastocisto (1.834), e no máximo $15 \%$ chegariam a fornecer linhagem tronco embrionária. Resumindo, dos 400.000 embriões congelados nos Estados Unidos, obter-seiam somente 275 linhagens. No Brasil provavelmente este número seria muito menor. Logo, não podemos contar somente com os embriões congelados no país para desenvolvimento de pesquisas e obtenção de células-tronco, mas também com aqueles embriões frescos considerados inviáveis que são descartados pelas clínicas.

Resumidamente, embriões de péssima qualidade a fresco podem resultar em gestações, mas quando congelados se tornam completamente inviáveis tanto para obtenção de gestação quanto para pesquisa; logo, a presença de embriões extranumerários tipo D, ou seja, que superam o número total de embriões permitidos para a transferência, não tem indicação de criopreservação. Então, pela lógica, em face de embriões extranumerários tipo $\mathrm{D}$, que quando congelados morrem, ao invés de serem descartados ${ }^{3,38}$, por que não doálos para pesquisa ${ }^{39}$, com a nobre finalidade de tentarmos obter linhagens de células-tronco?

Obviamente a doação para pesquisa só pode ser realizada em face da permissão do casal por meio de termos de consentimento esclarecido ${ }^{8,40}$.
Embriões de baixos escores morfológicos não podem ser considerados inviáveis por serem capazes, embora com uma freqüência muito baixa, de promoverem gestação. Estes mesmos embriões, quando criopreservados e posteriormente transferidos após descongelamento, mostraram taxa de gravidez irrisória, além de não resultarem em nenhuma gravidez viável. Podemos concluir que o congelamento dos mesmos se torna impraticável. Logo, quando extranumerários, não deveriam ser criopreservados, podendo então, ao invés de serem descartados, ser doados para pesquisa de células-tronco embrionárias ou outras pesquisas, desde que aprovadas pelo conselho de ética e pesquisa e pelo casal.

\section{Agradecimento}

Agradecemos ao NAP-SC Núcleo de Apoio à Publicação da Faculdade de Ciências Médicas da Santa Casa de São Paulo o suporte técnico-científico à publicação.

\section{Referências}

1. Thomson JA, Itskovitz-Eldor J, Shapiro SS, Waknitz MA, Swiergiel JJ, Marshall VS, et al. Embryonic stem cell lines derived from human blastocysts. Science. 1998;282(5391):1145-7.

2. Cohen CB. Use of "excess" human embryos for stem cell research: protecting women's rights and health. Womens Health Issues. 2000;10(3):121-6.

3. Choudhary M, Haimes E, Herbert M, Stojkovic M, Murdoch AP. Demographic, medical and treatment characteristics associated with couples' decisions to donate fresh spare embryos for research. Hum Reprod. 2004;19(9):2091-6.

4. Brouillet M, Turner L. Bioethics, religion, and democratic deliberation: policy formation and embryonic stem cell research. HEC Forum. 2005;17(1):49-63.

5. Solter D, Knowles BB. Immunosurgery of mouse blastocyst. Proc Natl Acad Sci USA. 1975;72(12):5099-102.

6. Reubinoff BE, Pera MF, Fong CY, Trounson A, Bongso A. Embryonic stem cell lines from human blastocysts: somatic differentiation in vitro. Nat Biotechnol. 2000;18(4):399-404.

7. Eiges R, Benvenisty N. Molecular view on pluripotent stem cells. FEBS Lett. 2002;529(1):135-41.

8. Lo B, Chou V, Cedars MI, Gates E, Taylor RN, Wagner $\mathrm{RM}$, et al. Informed consent in human oocyte, embryo and embryonic stem cell research. Fertil Steril. 2004;82(3):559-63.

9. Pera M, Reubinoff B, Trounson A. Human embryonic stem cells. J Cell Sci. 2000;113(Pt 1):5-10.

10. Trounson A, Pera M. Human embryonic stem cells. Fertil Steril. 2001;76(4):660-1.

11. Mitalipova M, Calhoun J, Shin S, Wininger D, Schulz T, Noggle S, et al. Human embryonic stem cell lines derived from discarded embryos. Stem Cells. 2003;21(5):521-6. 
12.Pennings G, Van Steirteghem A. The subsidiarity principle in the context of embryonic stem cell research. Hum Reprod. 2004;19(5):1060-4.

13. Asch R, Simerly C, Ord T, Ord VA, Schatten G. The stages at which human fertilization arrests: microtubule and chromosome configurations in inseminated oocytes which failed to complete fertilization and development in humans. Hum Reprod. 1995;10(7):1897-906.

14. Hardy K, Spanos S, Becker D, Iannelli P, Winston RM, Stark J. From cell death to embryo arrest: mathematical models of human preimplantation embryo development. Proc Natl Acad Sci USA. 2001;98(4):1655-60.

15. Puissant F, Van Rysselberge M, Barlow P, Deweze $\mathrm{J}$, Leroy F. Embryo scoring as a prognostic tool in IVF treatment. Hum Reprod. 1987;2(8):705-8.

16. Steer CV, Mills CL, Tan SL, Campbell S, Edwards RG. The cumulative embryo score: a predictive embryo scoring technique to select the optimal number of embryos to transfer in an in-vitro fertilization and embryo transfer programme. Hum Reprod. 1992;7(1):117-9.

17. Staessen C, Camus M, Bollen N, Devroey P, Van Steirteghem AC. The relationship between embryo quality and the occurrence of multiple pregnancies. Fertil Steril. 1992;57(3):626-30.

18. Scott L, Alvero R, Leondires M, Miller B. The morphology of human pronuclear embryos is positively related to blastocyst development and implantation. Hum Reprod. 2000; 15(11):2394-403.

19. Balakier H, MacLusky NJ, Casper RF. Characterization of the first cell cycle in human zygotes: implications for cryopreservation. Fertil Steril. 1993;59(2):359-65.

20. Giorgetti C, Terriou P, Auquier P, Hans H, Spach JL, Salzmann J, et al. Embryo score to predict implantation after in-vitro fertilization: based on 957 single embryo transfers. Hum Reprod. 1995;10(9):2427-31.

21. Payne D, Flaherty SP, Barry MF, Matthews CD. Preliminary observations on polar body extrusion and pronuclear formation in human oocytes using time-lapse video cinematography. Hum Reprod. 1997;12(3):532-41.

22. Desai NN, Goldstein J, Rowland DY, Goldfarb JM. Morphological evaluation of human embryos and derivation of an embryo quality scoring system specific for day 3 embryos: a preliminary study. Hum Reprod. 2000;15(10):2190-6.

23. Chen H, Qian K, Hu J, Liu D, Lu W, Yang T, et al. The derivation of two additional human embryonic stem cell lines from day 3 embryos with low morphological scores. Hum Reprod. 2005;20(8):2201-6.

24. Veeck LL. Atlas of the human oocyte and early concepus. Baltimore: Williams \& Wilkins; 1986.

25. Alikani M, Cohen J, Tomkin G, Garrisi GJ, Mack C, Scott RT. Human embryo fragmentation in vitro and its implications for pregnancy and implantation. Fertil Steril. 1999;71(5):836-42.

26. Jackson KV, Ginsburg ES, Hornstein MD, Rein MS, Clarke RN. Multinucleation in normally fertilized embryos is associated with an accelerated ovulation induction response and lower implantation and pregnancy rates in in vitro fertilization-embryo transfer cycles. Fertil Steril. 1998;70(1):60-6.
27. Hardarson T, Hanson C, Sjogren A, Lundin K. Human embryos with unevenly sized blastomeres have lower pregnancy and implantation rates: indications for aneuploidy and multinucleation. Hum Reprod. 2001;16(2):313-8.

28. Lightman A, Kol S, Wayner V, Vertman D, Manor D, Itskovitz-Eldor J. The presence of a sponsoring embryo in a batch of poor quality thawed embryos significantly increases pregnancy and implantation rate. Fertil Stertil. 1997;67(4):711-6.

29. Trounson A, Mohr L. Human pregnancy following cryopreservation, thawing and transfer of an eightcell embryo. Nature. 1983;305(5936):707-9.

30.Ziebe S, Petersen K, Lindenberg S, Andersen AG, Gabrielsen A, Andersen AN. Embryo morphology or cleavage stage: how to select the best embryos for transfer after in-vitro fertilization. Hum Reprod. 1997;12(7):1545-9.

31. Ebner T, Yaman C, Moser M, Sommergruber M, Polz W, Tews G. Embryo fragmentation in vitro and its impact on treatment and pregnancy outcome. Fertil Steril. 2001;76(2):281-5.

32. Shulman A, Ben-Nun I, Ghetler Y, Kaneti H, Shilon M, Beyth Y. Relationship between embryo morphology and implantation rate after in vitro fertilization treatment in conception cycles. Fertil Steril. 1993;60(1):123-6.

33. Antczak M, Van Blerkom J. Temporal and spatial aspects of fragmentation in early human embryos: possible effects on developmental competence and association with the differential elimination of regulatory proteins from polarized domains. Hum Reprod. 1999;14(2):429-47.

34. Salumets A, Tuuri T, Mäkinen S, Vilska S, Husu L, Tainio R, et al. Effect of developmental stage of embryo at freezing on pregnancy outcome of frozen-thawed embryo transfer. Hum Reprod. 2003;18(9):1890-5.

35. Edgar DH, Bourne H, Speirs AL, McBain JC. A quantitative analysis of the impact of cryopreservation on the implantation potential of human early cleavage stage embryos. Hum Reprod. 2000;15(1):175-9.

36. Park SP, Lee YJ, Lee KS, Ah Shin H, Cho HY, Chung $\mathrm{KS}$, etal. Establishment of human embryonic stem cell lines from frozen-thawed blastocysts using STO cell feeder layers. Hum Reprod. 2004;19(3):676-84.

37. Hoffman DI, Zellman GL, Fair CC, Mayer JF, Zeitz JG, Gibbons WE, et al. Cryopreserved embryos in the United States and their availability for research. Fertil Steril. 2003;79(5):1063-9.

38. Laruelle C, Englert Y. Psychological study of in vitro fertilization-embryo transfer participants' attitudes toward the destiny of their supernumerary embryos. Fertil Steril. 1995;63(5):1047-50.

39. American Society for Reproductive Medicine. Ethics Committee. Donating spare embryos for embryonic stem-cell research. Fertil Steril. 2002;78(5):957-60.

40.Ethics Committee of the American Society for Reproductive Medicine. Donating spare embryos for embryonic stem-cell research. Fertil Steril. 2004;82 Supp1 1:S224-7. 